\title{
BMJ Open Laryngopharyngeal reflux in war-torn Syria and its association with smoking and other risks: an online cross-sectional population study
}

Ameer Kakaje (D), Mohammad Marwan Alhalabi, Ayham Alyousbashi, Aya Hamid, Yousef Mahmoud

To cite: Kakaje A, Alhalabi MM, Alyousbashi A, et al. Laryngopharyngeal reflux in war-torn Syria and its association with smoking and other risks: an online cross-sectional population study. BMJ Open 2020;10:e041183. doi:10.1136/ bmjopen-2020-041183

- Prepublication history for this paper is available online. To view these files, please visit the journal online (http://dx.doi. org/10.1136/bmjopen-2020041183).

MMA and AA contributed equally.

Received 02 June 2020 Revised 17 October 2020 Accepted 05 November 2020

D) Check for updates

(c) Author(s) (or their employer(s)) 2020. Re-use permitted under CC BY-NC. No commercial re-use. See rights and permissions. Published by BMJ.

Damascus University Faculty of Medicine, Damascus, Syrian Arab Republic

Correspondence to

Dr Ameer Kakaje;

ameer.kakaje@hotmail.com

\section{ABSTRACT}

Objectives To demonstrate the burden of

laryngopharyngeal reflux (LPR) in Syria and its associated variables.

Design This is a cross-sectional study that used online questionnaires that included demographics, smoking, warrelated questions and reflux symptom index (RSI).

Setting This research was conducted online across Syria and included the general population.

Participants Participants who lived in Syria, agreed to participate, and responded to all the RSI questions were included. This research comprised 734 participants, with $94.6 \%$ response rate, $75.5 \%$ being females, and a mean age of 24 years.

Results Overall, $31.9 \%$ of subjects had symptoms suggestive of LPR. Participants who were 30 years and younger had fewer symptoms suggestive of LPR compared with the older group $\mathrm{p}=0.012(\mathrm{OR} 0.534 ; 95 \% \mathrm{Cl} 0.325$ to 0.877 ). While having an epigastric burning sensation, chest pain and indigestion were the most common symptoms, having a sore throat was the least common. Being distressed from war noises was associated with more symptoms $p=0.009$ (OR 1.562; $95 \% \mathrm{Cl} 1.117$ to 2.183). However, losing someone or changing place of living due to war were not significantly associated with these symptoms $p>0.05$. RSI scores were associated with cigarette and/or shisha smoking $p<0.05$. Finally, asthma, allergic disorders and having a job were associated with having LPR symptoms $p<0.05$. No significant findings were observed in consanguinity, marital status, educational level and socioeconomic status.

Conclusions War, smoking, asthma, allergies, respiratory conditions and having a job were associated with LPR symptoms. However, they may be associated with these symptoms independently from LPR; for instance, similar symptoms can be caused by the mental disorders from war, the unique environment and irritant substances of the laryngeal mucosa.

\section{INTRODUCTION}

Laryngopharyngeal reflux (LPR) is considered one of the most common extra-oesophageal complications of gastrooesophageal reflux (GORD). It occurs when the retrograde flow of the stomach reaches
Strengths and limitations of this study

- This study was about the general population across Syria during the war.

- It used a validated tool in the language of participants and simple and straightforward questions.

- It measured laryngopharyngeal reflux symptoms using the self-reported reflux symptom index questionnaire without a medical diagnosis.

- As it was an anonymous online study, people who were severely affected might have not been porperly targeted.

- No clinical examinations, or tests were conducted; it included a young population with a relatively high socioeconomic status.

the laryngopharynx and interacts with the upper aerodigestive tract. ${ }^{1}$ Data have shown that $60 \%$ of patients with GORD have LPR symptoms. ${ }^{2}$ Furthermore, it is debatable whether to consider LPR as an atypical presentation of GORD or an independent medical condition. ${ }^{3}$ The severity of symptoms cannot be determined by the severity of posterior laryngitis and pharyngeal reflux, or by using dual sensor $\mathrm{pH}$ probe. ${ }^{4}$ Nevertheless, visits to otolaryngologists were increased by $500 \%$ due to LPR in recent years, ${ }^{5}$ which caused a huge burden on the medical sector. Many laryngeal medical conditions are speculated to be associated with LPR, such as laryngitis, laryngeal carcinoma, subglottic stenosis, granulomas, contact ulcers and vocal cord nodules. Dysphonia can also be found in around half of patients with LPR.

Although LPR is quite common, the diagnosis is widely debated, as most studies are controversial. Otolaryngologists suggest that LPR is diagnosed when the laryngeal symptoms get resolved by proton pump inhibitors (PPIs). ${ }^{6}$ Scoring systems can also be used to evaluate the possibility of LPR, ${ }^{6}$ such as reflux 
symptom index (RSI). ${ }^{78}$ Having a score higher than 13 is indicative for an empirical therapeutic trial such as diet, lifestyle change, and implementing high doses of PPI. ${ }^{6}$

Syria has entered its eighth year of war at the time of the survey, and over $80 \%$ have been living under poverty line in a deteriorating economic status. This imposed a challenge to the healthcare sector from the lack of adequate staff and equipment. The Syrian population is chronically exposed to unusual substances from smoking habits, mate drinking, the unique environment and war aspects. ${ }^{910}$ In Syria, it was found that around half of the population suffered from allergic rhinitis, ${ }^{11}$ and $>90 \%$ of the population were exposed to war aspects. ${ }^{12}$ LPR has a wide variety of symptoms from the laryngeal irritation such as coughing, having a sore throat, hoarseness, dysphonia and globus pharyngeus. ${ }^{13}$ When LPR diagnosis is not promptly made, patients can suffer for a long time of symptoms that severely affect their quality of life. Most LPR symptoms and signs are unspecific and overlap with other aetiologies, such as voice abuse and irritations from smoking and alcohol drinking. Despite being quite common, LPR is not well-studied in the low- and middleincome countries. We aim to estimate the burden of symptoms associated with LPR and its different factors.

\section{METHODS AND MATERIALS \\ Sampling}

This is a cross-sectional study that collected online data from Social Media groups covering the period between 26 March 2019 and 26 April 2019, while covering various cities in Syria. Every responder who lived in Syria and aged 16 years and more was enrolled provided that they replied to every RSI question. Any responder with missing data in the RSI or basic demographic questions was excluded.

\section{Consent and approval for study}

Electronic informed consent was taken for participating in the research, and for using and publishing of the data.

\section{Questionnaires}

Socioeconomic status

Socioeconomic status (SES) was assessed by using three questions that included the education of the person or the working family member, their profession and the monthly family income. As a result, SES was divided into five categories: lower, upper-lower, lower-middle, upper-middle, and upper. This method was proved to be adequate in the Syrian society. ${ }^{12}$

\section{Reflux symptom index}

RSI is a self-administered questionnaire which was validated in Arabic. ${ }^{14}$ RSI relies on a scoring system based on LPR symptoms to evaluate the possibility of having LPR. ${ }^{78}$ These symptoms are hoarseness, throat clearing, mucus in the throat, difficulty swallowing, coughing after lying down or eating, difficulties of breathing, coughing, globus pharyngeus and heartburn. The scale ranges from
0 when answering 'no problem' to 5 when answering 'severe problem' for each item. The total score ranges from 0 to 45 . The cut-off point is set to 13 or more to suggest the possibility of LPR. ${ }^{8}$

\section{Other questions}

Demographic questions included gender, age, educational level, governorate of current living and having consanguineous parents. War exposure, both directly and indirectly, including change of place of living due to war, losing someone close and being distressed from war noises were also included in the questionnaires.

We asked the participants to declare having any medical condition. We also asked two simple questions about smoking which were "do you smoke cigarettes daily" and "do you regularly smoke shisha".

\section{Definitions}

Respiratory diseases in this study were defined as chronic bronchitis and chronic obstructive pulmonary medical condition. Education in the medical field included medicine, dentistry and pharmacy. Social science category included faculties of law, education, economy, literature and arts. We defined a low educational level as having a high school degree or lower. Allergic reactions are defined as having food or skin-related allergies. Being a specialist is defined as having a degree and working such as an engineer. Being a technician is being a worker with an institute degree. Labourer is a worker without a degree such as a builder and porter.

\section{Data process}

Data were processed using IBM SPSS software V.26 for Windows (SPSS, Illinois, USA). One-way analysis of variance (ANOVA), $\chi^{2}$ and Pearson's correlation tests were used. We calculated ORs and the $95 \%$ CIs by using the same software. Values $<0.05$ for the two-tailed $p$ values were considered statistically significant. Forward linear regression was also used to model the relationship between RSI scale and other variables.

\section{Patient and public involvement}

The research question did not interfere with patients' priorities as participants only had to do the survey in their free time with no follow-ups. Patients were involved by responding to the questionnaires estimating the symptoms they had. Their experience with war and symptoms had a major influence on their responses. However, results could be disseminated as the study had random participants from Syria with no particular risk factors. However, data should be cautiously generalised as it included higher SES and younger age groups than the normal population, and it is a self-reported online study.

\section{RESULTS}

Characteristics of the subjects are demonstrated in table 1. In our study, 820 received the questionnaire with a $94.6 \%$ response rate. Although 776 accepted to be enrolled, the 
Table 1 Characteristics of the subjects

\begin{tabular}{lll}
\hline Characteristic & $\begin{array}{l}\text { Frequency } \\
(\mathbf{n = 7 3 4 )}\end{array}$ & Percentage (\%) \\
\hline Gender & & \\
Male & 180 & 24.5 \\
Female & 554 & 75.5
\end{tabular}

Place of living

$\begin{array}{lrr}\begin{array}{l}\text { Damascus, Rif-Dimashq and } \\ \text { Aleppo }\end{array} & 474 & 70 \\ \text { Homs and Hama } & 102 & 15.1 \\ \text { Al-Jazira region } & 3 & 0.4 \\ \text { Southern Syria } & 18 & 2.7 \\ \text { Syrian coast } & 76 & 11.2 \\ \text { Idlib } & 4 & 0.5\end{array}$

\begin{tabular}{|c|c|c|}
\hline \multicolumn{3}{|l|}{ Educational level } \\
\hline Primary school & 1 & 0.1 \\
\hline High school & 42 & 5.7 \\
\hline $\begin{array}{l}\text { College or higher institute } \\
\text { certificate }\end{array}$ & 575 & 78.6 \\
\hline Masters or $\mathrm{PhD}$ & 114 & 15.6 \\
\hline
\end{tabular}

Smoking cigarettes

\begin{tabular}{|ccc|}
\hline No & 622 & 84.7 \\
\hline Yes regularly & 112 & 15.3 \\
\hline Smoking shisha & & \\
\hline No & 517 & 70.4 \\
Yes regularly & 217 & 29.6 \\
\hline SES level & & \\
\hline Lower & 14 & 1.9 \\
\hline Upper-lower & 151 & 20.6 \\
\hline Lower-middle & 177 & 24.1 \\
\hline Upper-middle & 372 & 50.7 \\
\hline Upper & 20 & 2.7 \\
\hline Employment & & \\
\hline Unemployed & 474 & 648 \\
\hline Employed & 258 & 35.2 \\
\hline Social status & & \\
\hline Single & 598 & 0.7 \\
\hline In a relationship & 5 & 0.8 \\
\hline Engaged & 35 & 11.8 \\
\hline Married & 86 & 0.4 \\
\hline Divorced & 3 & 0.3 \\
\hline Widowed & 2 & \\
\hline
\end{tabular}

sample consisted of 734 subjects as some replies were invalid or had some RSI questions unanswered. The sample comprised $180(24.5 \%)$ males and $554(75.5 \%)$ females. The mean age was $23.97 \pm 6.59$ years, and the age group of $18-30$ years constituted $88.3 \%$ of the sample. Other characteristics of war exposure, current medical conditions and reflux symptoms index of the subjects are demonstrated in table 2. Symptoms associated with LPR were found in $31.9 \%$ (95\% CI 28.2 to 35.4) of the sample.
Table 2 Other characteristics of war, current medical conditions and medications and reflux symptoms index results for the subjects

\begin{tabular}{|c|c|c|}
\hline Characteristic & Frequency & Percentage (\%) \\
\hline \multicolumn{3}{|l|}{ Changing area of living } \\
\hline No & 362 & 49.9 \\
\hline Yes, but not due to the war & 140 & 19.3 \\
\hline Yes & 223 & 30.8 \\
\hline \multicolumn{3}{|l|}{$\begin{array}{l}\text { A relative being endangered by } \\
\text { the war }\end{array}$} \\
\hline No & 228 & 31.2 \\
\hline Yes & 502 & 68.8 \\
\hline \multicolumn{3}{|l|}{ Losing someone due to the war } \\
\hline No & 417 & 57.2 \\
\hline Yes & 312 & 42.8 \\
\hline \multicolumn{3}{|l|}{$\begin{array}{l}\text { Being distressed from the war } \\
\text { noises }\end{array}$} \\
\hline No & 263 & 36 \\
\hline Yes & 468 & 64 \\
\hline \multicolumn{3}{|l|}{ Medical conditions } \\
\hline No & 435 & 72.4 \\
\hline Pulmonary & 6 & 1 \\
\hline Cardiac & 12 & 2 \\
\hline Endocrine & 53 & 8.8 \\
\hline Urinary & 7 & 1.2 \\
\hline Neurological & 20 & 3.3 \\
\hline Skeletal & 20 & 3.3 \\
\hline Asthma & 12 & 2 \\
\hline Allergic reaction & 36 & 6 \\
\hline \multicolumn{3}{|l|}{ Drugs } \\
\hline No & 394 & 59.3 \\
\hline Yes, some supplements & 37 & 5.6 \\
\hline Yes, over-the-counter drugs & 70 & 10.5 \\
\hline Yes, prescribed drugs & 163 & 24.5 \\
\hline \multicolumn{3}{|l|}{ Possibility for LPR } \\
\hline No & 500 & 68.1 \\
\hline Yes & 234 & 31.9 \\
\hline
\end{tabular}

Subjects who worked in the medical field had less symptoms $\mathrm{p}=0.033$.

Comparisons between subjects with negative and positive LPR symptoms are demonstrated in table 3 . The age group younger than 30 years had lower rates of symptoms $\mathrm{p}=0.012$ (OR $0.534 ; 95 \%$ CI 0.325 to 0.877 ) than the older group. Having any medical condition was associated with more symptoms compared with not having any medical condition $\mathrm{p}=0.003$ (OR 1.843; 95\% CI 1.223 to 2.780). This was also evident when associating the symptoms with having a chronic medical condition such as asthma $\mathrm{p}>0.0001$ (OR 13.750; 95\% CI 2.969 to 63.690 ), allergic reactions $\mathrm{p}=0.001$ (OR 3.074; 95\% CI 1.545 to 6.115) and pulmonary medical conditions $\mathrm{p}=0.029$ (OR 5.500; 
Open access

Table 3 Comparisons between subjects with negative and positive reflux symptoms index

\begin{tabular}{|c|c|c|c|c|c|c|}
\hline Characteristics & $\begin{array}{l}\text { Positive reflux } \\
\text { symptoms }\end{array}$ & Percentage (\%) & $\begin{array}{l}\text { Negative reflux } \\
\text { symptoms }\end{array}$ & Percentage (\%) & $P$ value & OR \\
\hline Gender & & & & & 0.084 & $1.390(0.956$ to 2.021$)$ \\
\hline Male & 48 & 20.5 & 132 & 26.4 & & \\
\hline Female & 186 & 79.5 & 368 & 73.6 & & \\
\hline
\end{tabular}

Consanguinity

$\begin{array}{lrrrr}\text { Negative } & 176 & 81.5 & 374 & 82.2 \\ \text { Positive } & 40 & 18.5 & 81 & 17.8 \\ \text { Marital status } & & & & 83.5 \\ \text { Single } & 184 & 79 & 814 & 16.5 \\ \text { Non-single } & 49 & 21 & & \end{array}$

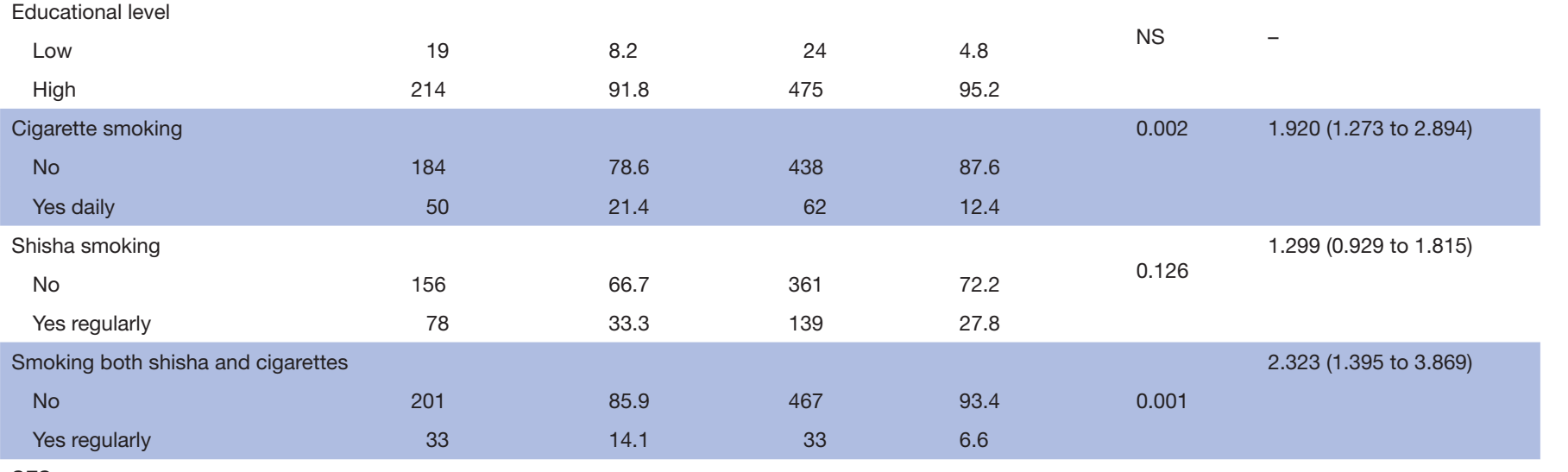

SES

\begin{tabular}{|c|c|c|c|c|c|c|}
\hline Low & 57 & 24.6 & 104 & 20.9 & & - \\
\hline Medium & 172 & 74.1 & 377 & 75.7 & 0.286 & \\
\hline High & 3 & 1.3 & 17 & 3.4 & 0.12 & \\
\hline Age group (years) & & & & & $0.005^{\star}$ & - \\
\hline $0-17$ & 9 & 3.8 & 6 & 1.2 & & \\
\hline $18-30$ & 193 & 82.5 & 455 & 91 & & \\
\hline $31-45$ & 25 & 10.7 & 32 & 6.4 & & \\
\hline $46+$ & 7 & 3 & 7 & 1.4 & & \\
\hline \multicolumn{7}{|l|}{ Working } \\
\hline Unemployed & 138 & 59.2 & 336 & 67.3 & 0.032 & 1.419 (1.029 to 1.957$)$ \\
\hline Employed & 95 & 40.8 & 163 & 32.7 & & \\
\hline Type of work & & & & & NS & - \\
\hline Labourer & 8 & 6.1 & 11 & 9.7 & & \\
\hline Clerk or in a restaurant & 10 & 7.6 & 11 & 9.7 & & \\
\hline Technician & 31 & 23.7 & 51 & 45.1 & & \\
\hline Specialist & 76 & 58 & 35 & 31 & & \\
\hline Employee & 6 & 4.6 & 5 & 4.4 & & \\
\hline Medical conditions except gastro & & & & & & - \\
\hline Negative & 115 & 61.8 & 319 & 77.2 & & \\
\hline Respiratory & 4 & 2.2 & 2 & 0.5 & $<0.0001 \dagger$ & \\
\hline Cardiac & 4 & 2.2 & 8 & 1.9 & & \\
\hline Endocrine & 11 & 5.9 & 42 & 10.2 & & \\
\hline Urinary & 3 & 0.3 & 4 & 1 & & \\
\hline Neurological & 10 & 5.4 & 10 & 2.4 & & \\
\hline Skeletal & 10 & 5.4 & 10 & 2.4 & & \\
\hline Asthma & 10 & 5.4 & 2 & 0.5 & & \\
\hline Allergic reaction & 19 & 10.2 & 16 & 3.9 & & \\
\hline
\end{tabular}




\begin{tabular}{|c|c|c|c|c|c|c|}
\hline Characteristics & $\begin{array}{l}\text { Positive reflux } \\
\text { symptoms }\end{array}$ & Percentage (\%) & $\begin{array}{l}\text { Negative reflux } \\
\text { symptoms }\end{array}$ & Percentage (\%) & $P$ value & OR \\
\hline No & 68 & 40.5 & 149 & 44 & & \\
\hline Yes a loved one or a close friend & 2 & 1.2 & 3 & 0.9 & & \\
\hline Yes a relative & 98 & 58.3 & 187 & 55.2 & & \\
\hline Negative & 68 & 29.2 & 195 & 39.2 & & \\
\hline Positive & 165 & 70.8 & 303 & 60.8 & & \\
\hline Changing place of living due to war & & & & & NS & - \\
\hline Negative & 116 & 50.2 & 246 & 49.8 & & \\
\hline Positive & 115 & 49.8 & 248 & 50.2 & & \\
\hline
\end{tabular}

${ }^{*}$ This $p$ value is among all age groups. However, $p=0.012$ when comparing age groups $(0-30)$ years with older than 30 years and $p=0.008$ when comparing age group $18-30$ years with older than 30 years.

$\dagger P$ value when comparing having any disease or not was $p=0.003$.

NS, not significant; SES, socioeconomic status.

95\% CI 0.994 to 30.428$)$ compared with not having any chronic medical condition.

Furthermore, when using RSI scores instead of cut-off points, higher scores were found with cigarette smoking $\mathrm{p}<0.0001$, shisha smoking $\mathrm{p}=0.035$ and smoking them both $p<0.0001$. No correlation was found when comparing RSI score with age or number of times changing place of living due to war $p>0.05$. When using one-way ANOVA test, SES classification was not associated with RSI scores $\mathrm{p}>0.05$.

The mean score of RSI in all subjects was $10.50 \pm 9.02$ (95\% CI 8.47 to 9.58). The mean score of each question of the index in subjects and number of people who had moderate or more severe symptoms in table 4 . The mean RSI score in each governorate and gender is shown in

Table 4 Mean scores and symptoms of each reflux symptom index question in the participants

\begin{tabular}{lcc}
\hline Characteristic & Mean score \pm SD & $\begin{array}{l}\text { Moderate or more } \\
\text { severe symptoms } \\
\text { prevalence (\%) }\end{array}$ \\
\hline Sore throat & $0.86 \pm 1.207$ & $69(9.4 \%)$ \\
\hline $\begin{array}{l}\text { Sputum production } \\
\text { Excessive secretions }\end{array}$ & $1.31 \pm 1.422$ & $146(19.9 \%)$ \\
\hline $\begin{array}{l}\text { Dysphagia } \\
\text { Coughing after eating, }\end{array}$ & $1.25 \pm 1.476$ & $137(18.7 \%)$ \\
sleeping or laying down & $0.87 \pm 1.309$ & $92(12.5 \%)$ \\
\hline $\begin{array}{l}\text { Breathing difficulties } \\
\text { Extreme coughing }\end{array}$ & $1.07 \pm 1.409$ & $113(13.1 \%)$ \\
episodes & $1.16 \pm 1.541$ & $131(17.9 \%)$ \\
\hline $\begin{array}{l}\text { A sense of a foreign } \\
\text { body in throat }\end{array}$ & $1.17 \pm 1.457$ & $112(15.3 \%)$ \\
\hline $\begin{array}{l}\text { Epigastric burning } \\
\text { sense, chest pain, } \\
\text { indigestion, GORD }\end{array}$ & $1.69 \pm 1.643$ & $199(27.1 \%)$ \\
\hline Total & $10.50 \pm 9.022$ & - \\
\hline
\end{tabular}

GORD, gastro-oesophageal reflux. figure 1. When using forward linear regression on RSI score with the significant variables from table 3, it was significant for medical condition category, smoking both shisha and cigarettes, being distressed from war noise, having a work. Regression results are demonstrated in table 5 .

\section{DISCUSSION}

Many studies proved that females had more reflux symptoms such as heartburn, ${ }^{15}$ which is not similar to our findings. Meanwhile, there are conflicting data about the effect of smoking on reflux disease. ${ }^{16}$ Although smoking might not be a dominant risk factor, it was suggested that smoking cessation with the appropriate pharmacological therapy might be beneficial in relieving severe GORD symptoms, ${ }^{17}$ and smoking cessation should be recommended for patients with GORD. ${ }^{18}$ In our study, cigarette smoking was associated with more LPR symptoms. The high prevalence of smoking might be one of the factors for the high prevalence of LPR symptoms in Syria, ${ }^{9}$ mainly that there are no regulations to prevent smoking in public places and transportations, causing a high exposure to all people as non-smokers are highly exposed to second-hand smoking. ${ }^{9}$ Smoking can also irritate the laryngeal mucosa causing coughing, hoarseness and other symptoms similar to LPR.

GORD was associated with respiratory diseases and asthma, ${ }^{19}$ and LPR was associated with allergic rhinitis. ${ }^{20}$ This is similar to our findings as LPR symptoms were correlated with the aforementioned risk factors. However, these medical conditions can cause symptoms that can be misinterpreted by RSI as LPR symptoms, particularly that allergic rhinitis was found in half of a studied population in Syria, ${ }^{11}$ which could explain the high prevalence of LPR symptoms.

A large number of patients with LPR struggled from higher rates of depression and had a lower health-related quality of life. ${ }^{21}$ In addition, the psychological factors 


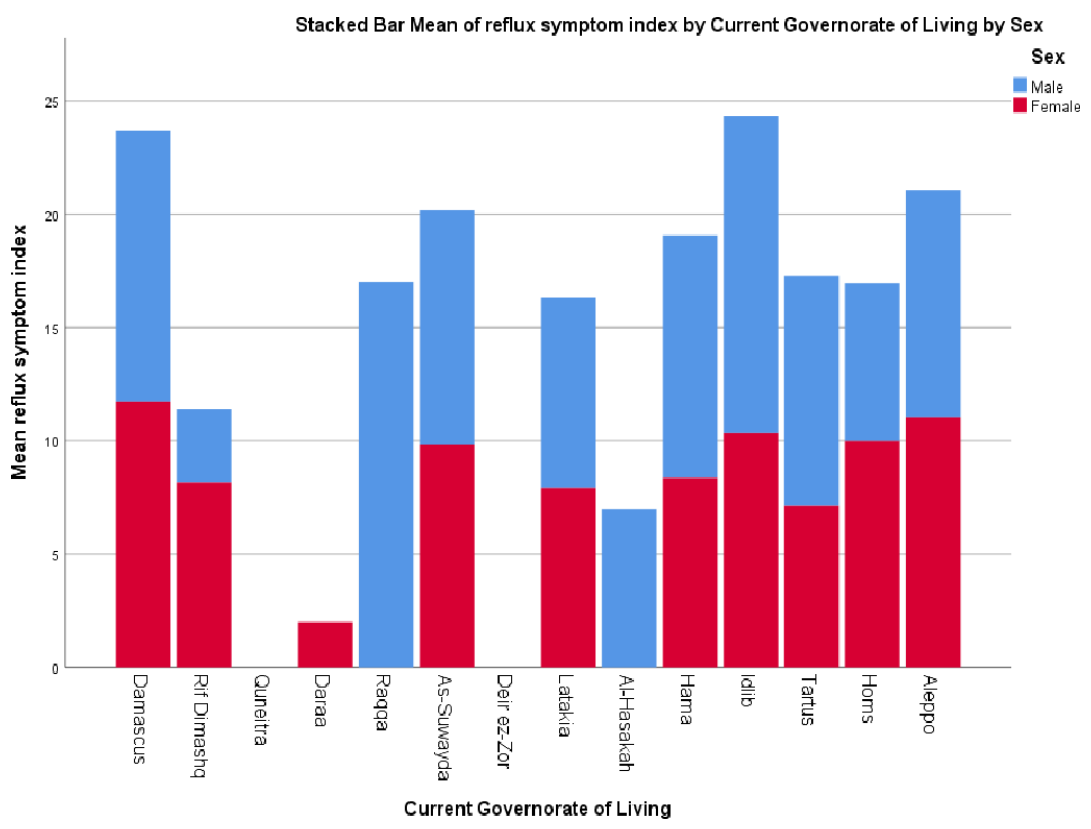

Figure 1 Mean reflux symptom index score in each governorate with gender prevalence.

caused a deterioration of the symptoms of GORD,${ }^{22}$ which was also associated with a decline in quality of life. ${ }^{23}$ This decline was dependent on the severity of LPR regardless of marital status and household income. ${ }^{24}$ We speculate that the high psychological stress and mental disorders in Syria ${ }^{12}$ could contribute to our findings as they might cause or amplify these symptoms. Similarly, we found an association between LPR symptoms and being distressed from war noises but not with marital status or other warrelated factors. LPR symptoms were also more frequent among subjects with a job, but we found no association with type of work.

GORD symptoms were more common among participants of lower income and educational level. ${ }^{2325}$ Furthermore, being from low or middle SES doubled the risk for severe symptoms of GORD despite adjusting for body mass index and smoking. ${ }^{26}$ These observations can be explained by the fact that people from a lower SES tend to have a lifestyle that encourages GORD. This is similar to Syrians in the lower educational levels who tend to have unique lifestyles that may encourage this as well. ${ }^{10}$ More symptoms that were associated with LPR were observed in our study in lower SES and educational level but with no statistical significance.
Untreated LPR may scar the true vocal folds, especially when it is corresponded with chronic vocal abuse. LPR is also associated with untreated GORD and Barret oesophagitis which is cancerous. ${ }^{27}$ Furthermore, GORD symptoms may precede the diagnosis of cancer in about $60 \%$ of patients with oesophageal adenocarcinoma. In the same study, the OR for oesophageal adenocarcinoma was 43.5 in individuals with long-standing and severe symptoms of reflux. ${ }^{28}$ As there is a dramatic increase in the incidence of carcinoma of the distal oesophagus, there is an urgent need for early recognition and treatment of GORD and the medical conditions associated with it.

We found a significant decrease in RSI scores in subjects who worked in the medical field, suggesting that these symptoms tend to be less frequent in this group, possibly due to prior awareness of such symptoms. The rest of the educational fields were not significantly associated with symptoms of LPR. The group of subjects aged 30 years and more had higher RSI scores than the younger subjects, but there was no correlation when directly comparing age and RSI scores. One study found that elderly people might have a higher baseline RSI. ${ }^{29}$ In contrast, another study found that patients in the older groups had significantly lower RSI. ${ }^{30}$

Table 5 Forward linear regression on RSI scores with its relevant statistically significant variables

\begin{tabular}{|c|c|c|c|c|c|c|c|}
\hline & \multirow[b]{2}{*}{ Model } & \multirow[b]{2}{*}{$\mathbf{R}^{2}$} & \multirow[b]{2}{*}{ Adjusted $\mathbf{R}^{2}$} & \multirow[b]{2}{*}{$\begin{array}{l}\text { SE of the } \\
\text { estimate }\end{array}$} & \multicolumn{3}{|c|}{ Change statistics } \\
\hline & & & & & $\mathrm{R}^{2}$ change & F change & $\begin{array}{l}\text { Sig. } F \\
\text { change }\end{array}$ \\
\hline \multirow[t]{4}{*}{ LPR score } & Medical condition category & 0.034 & 0.033 & 8.961 & 0.034 & 22.946 & $<0.001$ \\
\hline & Smoking both shisha and cigarettes & 0.070 & 0.067 & 8.800 & 0.036 & 24.972 & $<0.001$ \\
\hline & Being distressed from war noise & 0.091 & 0.087 & 8.705 & 0.021 & 15.264 & $<0.001$ \\
\hline & Having a work & 0.098 & 0.092 & 8.681 & 0.006 & 4.510 & 0.034 \\
\hline
\end{tabular}

LPR, laryngopharyngeal reflux; RSI, reflux symptom index. 


\section{Limitations}

We identify that this study has many biases and confounders. Despite LPR being commonly diagnosed based on symptoms, most measures lack some of the criteria to diagnose LPR. ${ }^{31}$ We used RSI which estimates having a probable LPR based on symptoms, and we did not use a medical diagnostic test. However, these symptoms are unspecific, and it is hard to distinguish from other aetiologies that can have similar symptoms such as asthma, smoking, alcohol consumption and chronic rhinosinusitis. Dysphonia is another symptom that is evaluated by RSI and was found to improve with treatment regardless of the aetiology. ${ }^{32}$ Furthermore, RSI has only met 13 out of 18 of the developmental criteria for LPR and lacks some of the common symptoms, but it was the only measurement tool that met at least one criterion in each domain. ${ }^{31}{ }^{33}$ RSI is also effective in showing responsiveness to treatment.

We could not include the severity of allergic reactions and asthma in this study. The change of RSI scores with empirical therapy was also beyond the study scope. The sampling was made online which made it hard to determine the population. However, this method was the most convenient due to the financial hurdles, and it ensures accessibility and anonymity for participants which is an important issue in Syria, mainly when asking questions regarding war. ${ }^{12}$

Another confounder was from the majority of the sample were young who lived in major cities and had a relatively higher SES level which may impose a hurdle in the generalisation of the findings. However, this study found no statistical significance when comparing LPR symptoms and the SES and educational level. Furthermore, lower RSI scores were found in participants who worked in the medical sector as they consisted $27.8 \%$ of the sample which may indicate that the prevalence could be even higher in the normal population as these participants had lower LPR symptoms compared with other works. Finally, self-reported measures tend to the overestimation of symptoms which could explain our findings.

In conclusion, diagnosing LPR is difficult and is commonly overlooked. It has a wide range of unspecific symptoms, and a proper diagnostic approach is needed to ameliorate patient care and prevent LPR complications, especially in high-risk populations. These symptoms were found in more than one-third of the population living in Syria. While epigastric burning sensation, chest pain and indigestion were the most common symptoms, a sore throat was the least common. War exposure, mainly distress from war noise, may increase the symptoms of LPR by a variety of ways which need more studies to be identified. Cigarette smoking, asthma, allergic disorders and having a job were also associated with symptoms of LPR. However, gender, marital status, educational level and shisha smoking were not associated with LPR.

Acknowledgements The authors sincerely appreciate the valuable contributions made by Kymberlee Simpson and acknowledge her efforts with this paper.
Contributors AK: first and senior author; conceptualisation; data curation; formal analysis; investigation; software; methodology; project administration; supervision; validation; original draft; writing — review and editing. MMA: data curation; formal analysis; software; original draft; writing — review and editing. AA: software; methodology; conceptualisation; validation; writing editing; investigation. AH: conceptualisation; original draft; writing—review. YM: project administration; writing editing; investigation.

Funding The authors have not declared a specific grant for this research from any funding agency in the public, commercial or not-for-profit sectors.

Competing interests None declared.

Patient and public involvement Patients and/or the public were involved in the design, or conduct, or reporting, or dissemination plans of this research. Refer to the 'Methods and materials' section for further details.

Patient consent for publication Not required.

Ethics approval This study was approved by Damascus University, Faculty of Medicine and approved according to the principles embodied in the Declaration of Helsinki.

Provenance and peer review Not commissioned; externally peer reviewed.

Data availability statement Data are available on reasonable request. Data will be made available on reasonable request.

Open access This is an open access article distributed in accordance with the Creative Commons Attribution Non Commercial (CC BY-NC 4.0) license, which permits others to distribute, remix, adapt, build upon this work non-commercially, and license their derivative works on different terms, provided the original work is properly cited, appropriate credit is given, any changes made indicated, and the use is non-commercial. See: http://creativecommons.org/licenses/by-nc/4.0/.

ORCID iD

Ameer Kakaje http://orcid.org/0000-0002-3949-6109

\section{REFERENCES}

1 Koufman JA. The otolaryngologic manifestations of gastroesophageal reflux disease (GERD): a clinical investigation of 225 patients using ambulatory 24 -hour $\mathrm{pH}$ monitoring and an experimental investigation of the role of acid and pepsin in the development of laryngeal injury. Laryngoscope 1991;101:1-78.

2 Richter JE, Ear RJE. Ear, nose and throat and respiratory manifestations of gastro-esophageal reflux disease: an increasing conundrum. Eur J Gastroenterol Hepatol 2004;16:837-45.

3 Koufman JA, Amin MR, Panetti M. Prevalence of reflux in 113 consecutive patients with laryngeal and voice disorders. Otolaryngol Head Neck Surg 2000;123:385-8.

4 Noordzij JP, Khidr A, Desper E, et al. Correlation of pH probemeasured laryngopharyngeal reflux with symptoms and signs of reflux laryngitis. Laryngoscope 2002;112:2192-5.

5 Altman KW, Stephens RM, Lyttle CS, et al. Changing impact of gastroesophageal reflux in medical and otolaryngology practice. Laryngoscope 2005;115:1145-53.

6 Ford $\mathrm{CN}$. Evaluation and management of laryngopharyngeal reflux. JAMA 2005;294:1534.

7 Belafsky PC, Postma GN, Koufman JA. The validity and reliability of the reflux finding score (RFS). Laryngoscope 2001;111:1313-7.

8 Belafsky PC, Postma GN, Koufman JA. Validity and reliability of the reflux symptom index (RSI). J Voice 2002;16:274-7.

9 Kakaje A, Alhalabi MM, Alyousbashi A, et al. Smoking habits in Syria and the influence of war on cigarette and shisha smoking 2020. doi:10.21203/rs.3.rs-15601/v1

$10 \mathrm{AaA}$ Ket al. Breastfeeding and acute lymphoblastic leukaemia: potential leukemogenesis in children in developing countries 2020. doi:10.21203/rs.3.rs-25489/v2

11 Kakaje A, Alhalabi MM, Alyousbashi A, et al. Allergic rhinitis and its epidemiological distribution in Syria: a high prevalence and additional risks in war time. Biomed Res Int 2020;2020:1-9.

12 Kakaje A, Zohbi RA, Aldeen OH, et al. Mental disorder and PTSD in Syria during wartime: a national-wide crisis 2020.

13 Vaezi MF, Hicks DM, Abelson TI, et al. Laryngeal signs and symptoms and gastroesophageal reflux disease (GERD): a critical assessment of cause and effect association. Clin Gastroenterol Hepatol 2003;1:333-44.

14 Farahat M, Malki KH, Mesallam TA. Development of the Arabic version of reflux symptom index. J Voice 2012;26:814.e15-814.e19. 
15 Kim YS, Kim N, Kim GH. Sex and gender differences in gastroesophageal reflux disease. J Neurogastroenterol Motil 2016;22:575-88.

16 Nilsson $\mathrm{M}$, Johnsen $\mathrm{R}$, Ye W, et al. Lifestyle related risk factors in the aetiology of gastro-oesophageal reflux. Gut 2004;53:1730-5.

17 Pandolfino JE, Kahrilas PJ. Smoking and gastro-oesophageal reflux disease. Eur J Gastroenterol Hepatol 2000;12:837-42.

18 Kohata Y, Fujiwara Y, Watanabe T, et al. Long-term benefits of smoking cessation on gastroesophageal reflux disease and healthrelated quality of life. PLoS One 2016;11:e0147860. doi:10.1371/ journal.pone.0147860

19 Molyneux ID, Morice AH. Airway reflux, cough and respiratory disease. Ther Adv Chronic Dis 2011;2:237-48.

20 Kakaje A, Alhalabi MM, Alyousbashi A, et al. Allergic rhinitis, asthma and gastro-esophageal reflux disease: a cross-sectional study on their reciprocal relations. 2020.

21 Joo Y-H, Song Y-S, Pae C-U. Relationship between depression and laryngopharyngeal reflux. psychiatry investigation 2017;14.

22 Wright CE, Ebrecht M, Mitchell R, et al. The effect of psychological stress on symptom severity and perception in patients with gastrooesophageal reflux. J Psychosom Res 2005;59:415-24.

23 Edman JS, Greeson JM, Roberts RS, et al. Perceived stress in patients with common gastrointestinal disorders: associations with quality of life, symptoms and disease management. Explore 2017;13:124-8.

24 Gong EJ, Choi KD, Jung H-K, et al. Quality of life, patient satisfaction, and disease burden in patients with gastroesophageal reflux disease with or without laryngopharyngeal reflux symptoms. J Gastroenterol Hepatol 2017;32:1336-40.
25 Moshkowitz M, Horowitz N, Halpern Z, et al. Gastroesophageal reflux disease symptoms: prevalence, sociodemographics and treatment patterns in the adult Israeli population. World $J$ Gastroenterol 2011;17:1332.

26 Nocon M, Keil T, Willich SN. Prevalence and sociodemographics of reflux symptoms in Germany--results from a national survey. Aliment Pharmacol Ther 2006;23:1601-5.

27 Brown JSC. Laryngopharyngeal reflux in StatPearls [Internet]. Treasure Island (FL): StatPearls Publishing. Available: https://www. ncbi.nlm.nih.gov/books/NBK519548/ [Accessed 4 Jun 2019]

28 Lagergren J, Bergström R, Lindgren A, et al. Symptomatic gastroesophageal reflux as a risk factor for esophageal adenocarcinoma. N Engl J Med 1999;340:825-31.

29 Lee YC, Lee JS, Kim SW, et al. Influence of age on treatment with proton pump inhibitors in patients with laryngopharyngeal reflux disease: a prospective multicenter study. JAMA Otolaryngol Head Neck Surg 2013;139:1291.

30 Lechien JR, Finck C, Huet K, et al. Impact of age on laryngopharyngeal reflux disease presentation: a multi-center prospective study. Eur Arch Otorhinolaryngol 2017;274:3687-96.

31 Francis DO, Patel DA, Sharda R, et al. Patient-reported outcome measures related to laryngopharyngeal reflux. Otolaryngology 2016;155:923-35.

32 Kavookjian H, Irwin T, Garnett JD, et al. The reflux symptom index and symptom overlap in dysphonic patients. Laryngoscope 202010.1002/lary.28506. [Epub ahead of print: 06 Feb 2020].

33 Lechien JR, Bobin F, Muls V, et al. Validity and reliability of the reflux symptom score. Laryngoscope 2020;130:E98-107. 